Dhaka Univ. J. Biol. Sci. 27(2): 183-189, 2018 (July)

\title{
CYTOGENETICAL CHARACTERIZATION OF ACALYPHA INDICA L. IN BANGLADESH
}

\author{
Ishrat Jahan Bonna, Sheikh Shamimul Alam and Syeda Sharmeen Sultana* \\ Cytogenetics Laboratory, Department of Botany, University of Dhaka, \\ Dhaka-1000, Bangladesh
}

Key words: Cytogenetical characterization, CMA, DAPI, Acalypha indica

\begin{abstract}
Acalypha indica L. was cytogenetically characterized after staining with orcein, CMA and DAPI. In this species "Simple Chromocenter Type" of interphase nuclei was observed with a few small heterochromatin blocks following orcein staining. Prophase chromosomes showed "Interstitial Type" of staining pattern with orcein which indicated the tendency of aggregation of heterochromatin in interstitial regions of chromosome. This plant was found to possess $2 \mathrm{n}=20$ metacentric chromosomes. The total length of $2 \mathrm{n}$ chromosome complement was $55.33 \mu \mathrm{m}$. Individual chromosome length ranged from 1.84 to $3.50 \mu \mathrm{m}$. The relative length of each chromosome ranged from 0.03 to 0.06 . After staining with CMA, three bright bands were observed at different locations of chromosomes. A total of four DAPI-positive bands were also found of which two bands were centromeric and other two were entirely fluoresced with DAPI. The results of the cytological investigation may be useful for future characterization of this plant species.
\end{abstract}

\section{Introduction}

The genus Acalypha belongs to Euphorbiaceae consisting of about 450 species $^{(1)}$. Acalypha is widespread geographically, with its greatest diversity in the tropics and subtropics, and only a few annual species in temperate regions ${ }^{(1-3)}$. Among these only three species viz. A. ciliata Forssk., A. hispida Burm. f. and A. indica L. were reported from Bangladesh of which A. indica L. was found throughout Bangladesh whereas the other two species showed restricted occurrence ${ }^{(4)}$.

Acalypha indica L. commonly known as Muktajhury, is an annual herb used as expectorent, diuretic, emetic and laxative. Fresh leaf juice of this plant is useful in arthritis and scabies. Dry leaf powder of this plant is used in bed sores ${ }^{(1,4-5)}$.

Although Acalypha indica has considerable medicinal values, no report about the genetic information is available in Bangladesh ${ }^{(4)}$. A few studies from different parts of the world tried to characterize this species with classical karyotype analysis but their work was confined mainly to $2 \mathrm{n}$ chromosome count ${ }^{(6-8)}$. Except $2 \mathrm{n}$ chromosome number limited cytogenetical information is available for this species.

*Author for correspondence: <rumana_botany@yahoo.com>. 
For authentic identification of a specimen, genomic information is essential. Karyotype analysis is one of the conventional methods that gives a preliminary idea about the genome of a specimen. The conventional karyotype analysis alone is unable to express critically the differences among closely related species since these species usually possess similar $2 \mathrm{n}$ chromosomes numbers and even other karyotype features ${ }^{(9-10)}$. Moreover, the consideration of chromosome length, arm ratio, position and number of secondary constrictions are not always sufficient to differentiate individual chromosome. Minute deletion, inversion, tandem duplication, etc. could not be possible to detect by conventional karyotype analysis.

In such a case, different cytogenetical approaches should be undertaken. Staining with DNA-base specific banding with fluorochromes such as chromomycin $\mathrm{A}_{3}$ (CMA) and 4'-6 diamidino-2-phenylindole (DAPI) is one of such approaches for karyotype study of related species. Fluorescent banding is quite satisfactory for detailed and critical chromosome analysis such as identification of individual chromosome, determination of amount and location of AT- and GC-rich base pairs in chromosomes, etc.(11-13). Fluorescent karyotype analyses were able to solve taxonomic problems of different plant species ${ }^{(14-17)}$. Therefore, in the present study, a combination of classical and fluorescent cytogenetical analyses has been carried out to characterize Acalypha indica found in Bangladesh.

\section{Materials and methods}

Acalypha indica L. was collected from Agargaon, Dhaka. Healthy roots of A. indica were collected and pretreated with 8-hydroxyquinoline $(0.002 \%)$ for $1 \mathrm{hr}$ at $18^{\circ} \mathrm{C}$ followed by $15 \mathrm{~min}$ fixation in $45 \%$ acetic acid at $4^{\circ} \mathrm{C}$ and preserved in $70 \%$ alcohol at $4^{\circ} \mathrm{C}$ for future use. These were then hydrolyzed in a mixture of $1 \mathrm{~N} \mathrm{HCl}$ and $45 \%$ acetic acid $(2: 1)$ at $60^{\circ} \mathrm{C}$ for $2 \mathrm{~min}$. The root tips were stained and squashed in 1\% aceto-orcein for $3.30 \mathrm{hrs}$. These were observed under compound microscope (Nikon Eclipse 100). For CMA- and DAPI banding, Alam and Kondo's(12) method was used with slight modification. After hydrolysing and dissecting, the materials were squashed with $45 \%$ acetic acid. The cover glasses were removed quickly on dry ice and allowed to air dry for at least $24 \mathrm{hrs}$ before study. The air-dried slides were first pre-incubated in McIlvaine's buffer ( $\mathrm{pH} 7.0)$ for 30 min followed by distamycin A $(0.1 \mathrm{mg} / \mathrm{ml})$ treatment for $10 \mathrm{~min}$. The slides were rinsed mildly in McIlvaine's buffer supplemented with $\mathrm{MgSO}_{4}(5 \mathrm{mM})$ for $15 \mathrm{~min}$. One drop of CMA $(0.1 \mathrm{mg} / \mathrm{ml})$ was added to the materials for $1 \mathrm{hr}$ in a humid chamber and then rinsed with Mcllvaine's buffer with $\mathrm{MgSO}_{4}$ for $10 \mathrm{~min}$. Slides were mounted in $50 \%$ glycerol and kept at $4^{\circ} \mathrm{C}$ for overnight before observation. These were observed under Nikon (Eclipse 50i) fluorescent microscope with blue violet (BV) filter cassette. For DAPIstaining, after $24 \mathrm{hrs}$ of air drying, the slides were first pre-incubated in Mcllvaine's buffer ( $\mathrm{pH} \mathrm{7.0)}$ for $25 \mathrm{~min}$ and treated in actinomycin D $(0.25 \mathrm{mg} / \mathrm{ml})$ for $10 \mathrm{~min}$ in a humid chamber. The slides were immersed in DAPI solution $(0.01 \mathrm{mg} / \mathrm{ml})$ for $1 \mathrm{hr}$ and 
mounted with 50\% glycerol. These were observed under a Nikon (Eclipse 50i) fluorescent microscope with UV filter cassette.

\section{Results and Discussion}

Orcein staining: A few small deeply stained heterochromatic blocks were observed in the interphase nuclei of Acalypha indica (Fig. 1). The prophase chromosomes were found to be stained at the interstitial regions of chromosomes (Fig. 2). According to Tanaka(18), this type of interphase nuclei is known as simple chromocenter type and prophase chromosomes are called interstitial type.

Acalypha indica was found to possess $2 \mathrm{n}=20$ chromosomes in this investigation (Figs 3 and 10, Tables 1 - 2). Similar chromosome number for this species was reported earlier by Fedorov ${ }^{(6)}$. Besides, $2 \mathrm{n}=14$ was also reported for this species which indicated the existence of different cytotype for this species( ${ }^{(6)}$.

This species was found to possess all metacentric chromosomes with a centromeric formula of $20 \mathrm{~m}$ (Fig. 10, Tables 1 - 2). The total length of $2 \mathrm{n}$ chromosome complement was $55.33 \mu \mathrm{m}$. Individual chromosome length ranged from 1.84 to $3.50 \mu \mathrm{m}$. The relative length of each chromosome ranged from 0.03 to 0.06 (Table 2). In this species, the range of chromosomal length was almost negligible i.e. difference between the smallest and largest chromosomes was about $1.66 \mu \mathrm{m}$. As a result, no gradual decrease of chromosomal length was observed in its karyotype (Table 1). These features indicated that $A$. indica has a strict symmetric karyotype. Stebbins ${ }^{(19)}$ mentioned that the symmetric karyotypes indicate primitive character and from that point of view A. indica is a plant of primitive nature.

CMA banding: A few small CMA positive bands were observed in interphase nuclei and prophase chromosomes after CMA staining in $A$. indica (Figs 4 - 5, 11). In A. indica, the total GC-rich region was $4.95 \mu \mathrm{m}$ which occupied about $8.95 \%$ of total chromatin length (Table 2). Three CMA-positive bands were observed in two different pairs of chromosomes (Figs 6, 11, Table 2). Heteromorphicity in respect of banding pattern was observed in chromosome pair I where a member showed CMA-positive band on its short arm and its homologue had CMA-positive bright band on the long arm (Fig. 11). This might be due to the occurence of its inversion in respective chromosomes. Heteromorphicity in respect of banding pattern was also observed in chromosome pair $\mathrm{V}$ after CMA staining. Here, a member had bright CMA-band at short arm whereas its homologoue did not show any band (Fig. 11). This heteromorphicity may be occured due to the deletion of GC-rich bases from the respective chromosome.

DAPI banding: After DAPI staining in A. indica, a few DAPI positive bands were observed in interphase nuclei and prophase chromosomes (Figs $7-8,12$ ). The total length of DAPI-banded region was $11.27 \mu \mathrm{m}$ which occupied about $20.37 \%$ of total chromatin length (Table 2). Four DAPI-positive bands were observed at different locations of 

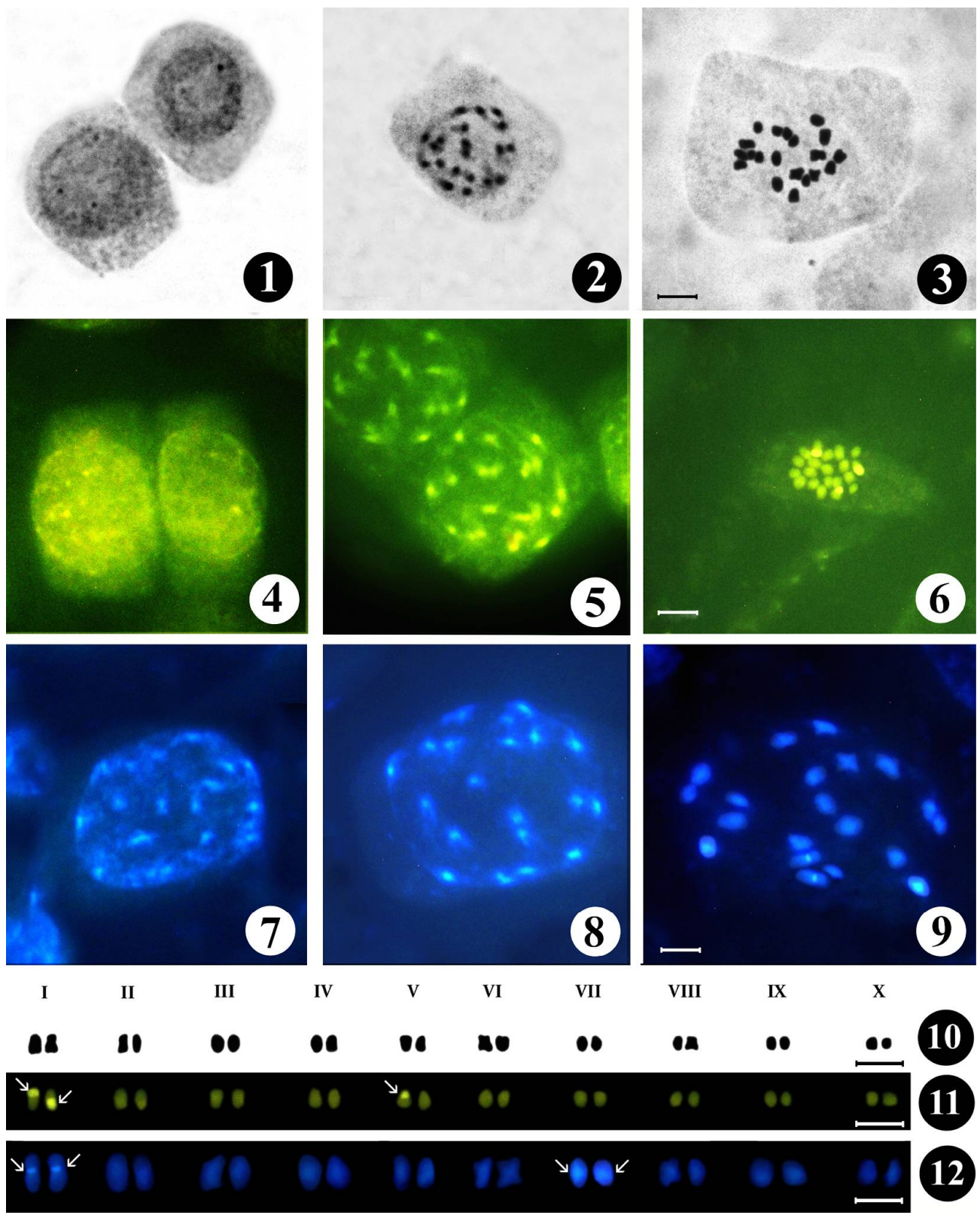

10

Figs 1-12. Orcein-, CMA- and DAPI- stained mitotic interphase nuclei, prophase chromosomes, metaphase chromosomes and karyotypes of Acalypha Indica L. 1. Orcein-stained mitotic interphase nuclei, 2. Orceinstained mitotic prophase chromosomes, 3. Orcein-stained mitotic metaphase chromosomes, 4. CMAstained mitotic interphase nuclei, 5. CMA-stained mitotic prophase chromosomes, 6. CMA-stained mitotic metaphase chromosomes, 7. DAPI-stained mitotic interphase nuclei, 8. DAPI-stained mitotic metaphase chromosomes, 9. DAPI-stained mitotic metaphase chromosomes, 10. Orcein-karyotype prepared from mitotic metaphase chromosomes, 11. CMA-karyotype prepared from mitotic metaphase chromosomes, 12. DAPI-karyotype prepared from mitotic metaphase chromosomes. Bar $=5 \mu \mathrm{m}$. 
Table 1. Length $(\mu \mathrm{m})$, arm ratio, centromeric index, relative length and centromeric type of metaphase chromosomes of Acalypha indica $\mathrm{L}$.

\begin{tabular}{lccccccc}
\hline $\begin{array}{l}\text { Chromo- } \\
\text { some } \\
\text { pair }\end{array}$ & $\begin{array}{c}\text { Long } \\
\text { arm } \\
(\mathrm{l}) \mu \mathrm{m}\end{array}$ & $\begin{array}{c}\text { Short } \\
\text { arm }(\mathrm{s})\end{array}$ & $\begin{array}{c}\text { Total } \\
\text { length (T) }\end{array}$ & $\begin{array}{c}\text { Arm } \\
\text { ratio } \\
(\mathrm{m})\end{array}$ & $\begin{array}{c}\text { Relative } \\
\text { length } \\
(\mathrm{RL})\end{array}$ & $\begin{array}{c}\text { Centromeric } \\
\text { index } \\
(\mathrm{CI})\end{array}$ & $\begin{array}{c}\text { Centromeric } \\
\text { type (CT) }\end{array}$ \\
\hline $\mathrm{I}$ & 1.75 & 1.75 & 3.50 & 1.00 & 0.06 & 50.00 & $\mathrm{~m}$ \\
& 1.61 & 1.56 & 3.17 & 1.03 & 0.06 & 49.21 & $\mathrm{~m}$ \\
$\mathrm{II}$ & 1.56 & 1.56 & 3.12 & 1.00 & 0.06 & 50.00 & $\mathrm{~m}$ \\
& 1.56 & 1.56 & 3.12 & 1.00 & 0.06 & 50.00 & $\mathrm{~m}$ \\
III & 1.52 & 1.52 & 3.04 & 1.00 & 0.05 & 50.00 & $\mathrm{~m}$ \\
& 1.52 & 1.52 & 3.04 & 1.00 & 0.05 & 50.00 & $\mathrm{~m}$ \\
IV & 1.50 & 1.50 & 3.00 & 1.00 & 0.05 & 50.00 & $\mathrm{~m}$ \\
& 1.50 & 1.50 & 3.00 & 1.00 & 0.05 & 50.00 & $\mathrm{~m}$ \\
V & 1.50 & 1.50 & 3.00 & 1.00 & 0.05 & 50.00 & $\mathrm{~m}$ \\
& 1.50 & 1.50 & 3.00 & 1.00 & 0.05 & 50.00 & $\mathrm{~m}$ \\
VI & 1.33 & 1.33 & 2.66 & 1.00 & 0.05 & 50.00 & $\mathrm{~m}$ \\
& 1.33 & 1.29 & 2.62 & 1.03 & 0.05 & 49.24 & $\mathrm{~m}$ \\
VII & 1.33 & 1.29 & 2.62 & 1.03 & 0.05 & 49.24 & $\mathrm{~m}$ \\
& 1.33 & 1.29 & 2.62 & 1.03 & 0.05 & 49.24 & $\mathrm{~m}$ \\
VIII & 1.33 & 1.29 & 2.62 & 1.03 & 0.05 & 49.24 & $\mathrm{~m}$ \\
& 1.29 & 1.27 & 2.56 & 1.02 & 0.05 & 49.61 & $\mathrm{~m}$ \\
IX & 1.17 & 1.17 & 2.34 & 1.00 & 0.04 & 50.00 & $\mathrm{~m}$ \\
& 1.17 & 1.17 & 2.34 & 1.00 & 0.04 & 50.00 & $\mathrm{~m}$ \\
X & 1.06 & 1.06 & 2.12 & 1.00 & 0.04 & 50.00 & $\mathrm{~m}$ \\
& 0.92 & 0.94 & 1.84 & 1.00 & 0.03 & 50.00 & $\mathrm{~m}$ \\
\hline \multirow{2}{*}{} & Grand total $=55.33 \mu \mathrm{m}$ & & & & \\
& & & & & & &
\end{tabular}

$\mathrm{m}=$ Metacentric chromosome.

Table 2. Cytogenetical analyses of Acalypha indica after Orcein, CMA, DAPI staining.

\begin{tabular}{ccccccccccc}
\hline $2 \mathrm{n}$ & $\begin{array}{c}\text { Total } \\
\text { chroma- } \\
\text { tin } \\
\text { length } \\
(\mu \mathrm{m})\end{array}$ & $\begin{array}{c}\text { Range of } \\
\text { individual } \\
\text { chromosomal } \\
\text { length } \\
(\mu \mathrm{m})\end{array}$ & $\begin{array}{c}\text { Range of } \\
\text { relative } \\
\text { length } \\
(\mathrm{RL})\end{array}$ & $\begin{array}{c}\text { Centro- } \\
\text { meric } \\
\text { formula }\end{array}$ & $\begin{array}{c}\text { No. of } \\
\text { CMA- } \\
\text { bands }\end{array}$ & $\begin{array}{c}\text { CMA- } \\
\text { banded } \\
\text { region } \\
(\mu \mathrm{m})\end{array}$ & $\begin{array}{c}\text { GC- } \\
\text { rich } \\
\text { repeats }\end{array}$ & $\begin{array}{c}\text { DAPI- } \\
\text { bands }\end{array}$ & $\begin{array}{c}\text { DAPI- } \\
\text { banded } \\
\text { region } \\
(\mu \mathrm{m})\end{array}$ & $\begin{array}{c}\text { AT-rich } \\
\text { repeats }\end{array}$ \\
\hline 20 & 55.33 & $1.84-3.50$ & $0.03-0.06$ & $20 \mathrm{~m}$ & 3 & 4.95 & 8.95 & 4 & 11.27 & 20.37 \\
\hline
\end{tabular}

$\mathrm{m}=$ Metacentric chromosome. 
metaphase chromosomes (Figs 9, 12). Each member of the pair I showed centromeric DAPI bands (Fig. 12). Entirely DAPI-fluoresced bands were observed in both the homologue members of chromosome pair VII (Fig. 12). These DAPI-fluoresced large areas indicated possible tandem duplication of AT-rich region.

The above cytogenetical information obtained by conventional and fluorescent staining of chromosomes is probably the first report for Acalypha indica L. which may help in authentic characterization of this plant species in Bangladesh.

\section{Acknowledgement}

Authors are thankful to Professor Dr. Momtaz Begum, Department of Botany, University of Dhaka for her cordial help and co-operation in identification of the plant. Sincere thanks are due to the Chairman, Department of Botany, University of Dhaka for facilities of maintaining the plant in the Botanical Garden.

\section{References}

1. Sagun VG, GA Levin, PCV Welzen 2010. Revision and phylogeny of Acalypha (Euphorbiaceae) in Malesia. Blumea 55: 21-60.

2. Webster GL 1994. Synopsis of the genera and suprageneric taxa of Euphorbiaceae. Ann. Missouri Bot.Gard. 81: 33-144.

3. Radcliffe-Smith A 2001. Genera Euphorbiacearum. Royal Botanic Garden, Kew, Richmond.

4. Ahmed ZU, MA Hassan, ZNT Begum, M Khondker, SMH Kabir, M Ahmad, ATA Ahmed, AKA Rahman and EU Haque 2008. Encyclopedia of flora and fauna of Bangladesh. Angiosperms: Dicotyledons (Balsaminaceae - Euphorbiaceae). Asiat. Soc. Bangladesh. 7: 376-379.

5. Ghani A 1998. Medicinal plants of Bangladesh. J. Asiat. Soc. Bangladesh. pp. 460.

6. Fedorov AA 1969. Chromosome numbers of flowering plants. Acad. Sci. USSR. pp. 274.

7. Soontornchainaksaeng $\mathrm{P}$ and K Chaiyasut 1999. Cytogenetic investigation of some Euphorbiaceae in Thailand. Cytologia 64: 229-234.

8. Elumalai R and R Selvaraj 2013. Karyomorphological studies in some taxa of Euphorbiaceae. Int. J. Cur. Tr. Res. 2 (1): 210-218.

9. Khatun M and SkS Alam 2010. Conformation of species status of Corchorus trilocularis by differential chromosome banding and isozyme assay. Cytologia 75: 83-88.

10. Khatun M, SS Sultana, H Ara, MN Islam and SkS Alam 2011. Differential chromosome banding and isozyme assay of three Corchorus spp. Cytologia 76: 27-32.

11. Schweizer D 1976. Reverse fluorescent chromosome banding with Chromomycin and DAPI. Chromosoma 58: 307-324.

12. Alam SkS and K Kondo 1995. Differential staining with orecein, Giemsa, CMA and DAPI for comparative chromosome study of 12 species of Australian Drosera (Droseraceae). Amer. J. Bot. 82: 1278-1286. 
13. Kondo T and M Hizume 1982. Banding for the chromosomes of Cryptomeria japonica D. Don. Japan J. Forest. Soc. 64: 356-358.

14. Jessy NS, R Begum, M Khatun and SkS Alam 2005. Differential fluorescent chromosome banding of four species in Haworthia duval (Aloaceae). Cytologia 70: 435-440.

15. Akter S and SkS Alam 2005. Differential fluorescent banding pattern in three varieties of Cicer arietinum L. (Fabaceae). Cytologia 70: 441-445.

16. Islam M and SkS Alam 2011. Karyotype characterization with fluorescent banding in one released and two wild germplasms of Hibiscus cannabinus L. Cytologia 76: 223-227.

17. Sultana SS, H Ara and SkS Alam 2011. Karyotype analysis with orcein and CMA in two species of Alocasia (Schott) G. Don. Bangladesh J. Bot. 40: 53-56.

18. Tanaka R 1971. Type of resting nuclei in Orchidaceae. Bot. Mag. Tokyo 84: 118-122.

19. Stebbins GL 1971. Chromosomal evolution in higher plants. Addison-Wesley publishing company, California, USA. pp. 208.

(Manuscript received on 25 February, 2018; revised on 23 May, 2018) 